\title{
Nitrocellulose/glycidylazide-polymer/erythritol-tetranitrate Energetic Nanocomposites Fabricated Using a Sol-gel-freeze Method
}

\author{
Mi Zhang ${ }^{1}$, Yi Wang ${ }^{1 *}$, Hao Huang ${ }^{2}$, Feifei Shang ${ }^{3}$, Xiaolan Song ${ }^{4^{*}}$ \\ ${ }^{1}$ School of Materials Science and Engineering, North University of China, Taiyuan, China \\ ${ }^{2}$ China North Industries Group Corporation Limited, Beijing, China \\ ${ }^{3}$ Teaching and Research Support Center, Army Academy of Armored Forces, Beijing, China \\ ${ }^{4}$ School of Environment and Safety Engineering, North University of China, Taiyuan, China \\ E-mail: wangyi528528@aliyun.com; songxiaolan00@126.com
}

\begin{abstract}
Nitrocellulose/glycidylazide-polymer/erythritol-tetranitrate (NC/GAP/ETN) nanocomposite energetic materials were fabricated using a sol-gel-freeze method. The microstructure, crystal phase and molecular structure were characterized by SEM, XRD and IR. Meanwhile, the thermal properties, energy properties and mechanical sensitivity of the composites were also studied. The ETN particle size is about 500nm, and few partial gel skeleton collapsed and contracted. No phase transformation of the ETN occurred before or after fabrication, and the molecular structures of the ETN, NC and GAP did not change. There is only one exothermic peak in the DSC traces and the peak temperature of nanocomposites are approximately $62^{\circ} \mathrm{C}, 24^{\circ} \mathrm{C}$ and $41^{\circ} \mathrm{C}$ earlier than raw ETN. The $I_{s p}$, $C^{*}, T_{c}, M_{c}$, and $Q_{p}$ increase with the weight percentage of ETN increasing, and the oxygen balance of three samples is still negative. The mechanical sensitivity are all lower than raw ETN. The energy performance and safety performance of samples are improved.
\end{abstract}

Keywords: NC/GAP/ETN, sol-gel-freeze; thermolysis, energetic performance, mechanical sensitivity.

\section{Introduction}

Erythritol-tetranitrate (ETN) is a typical solid crystalline explosive. Despite its simple preparation method, the study was once put on hold due to the source and cost constraints of the raw erythritol. The chemical structure is similar to that of nitroglycerin $[1,2]$, and its physical properties and explosive properties are similar to those of PETN $[3,4]$. It is one of the few positive oxygen balance explosives (OB is $+26.48 \%$ calculated by $\mathrm{CO},+5.3 \%$ calculated by $\mathrm{CO}_{2}$ ), and the fusion point is about $61^{\circ} \mathrm{C}$. Hence, ETN is expected to be used in mixed explosives to improve performance. At present, there are few researches on the application of ETN in explosives, and its various properties, such as structural parameters, detonation performance, sensitivity performance and stability performance are only reported in a small amount [5-9]. Therefore, the research on ETN is of great significance.

The combustion and explosive properties of energetic materials are greatly affected by its microstructure. The nanocomposite energetic materials can promote the mass transfer and heat transfer process of the materials due to the nanoscale contact between the components, which greatly increases the energy release rate of the system and reduces the sensitivity. In addition, nanocomposites can effectively avoid agglomeration problems and exhibit synergy. Therefore, nanocomposite energetic materials have become a hot topic in recent years. Nanocomposite energetic materials can be prepared by different methods, such as sol-gel method [10-12], mechanical grinding method [13-16], spraying evaporation method [17], freezing evaporation method [18-20], solvent/non-solvent method [21], electrospinning technology [22] and electrostatic spraying method [23]. The sol-gel method has become an important method for preparing nanocomposite energetic materials in recent years due to its safe operation, simple preparation process and controllable size. At present, the researchers at home and abroad prepared the nanocomposite energetic materials by sol-gel method with inert materials as the gel skeleton mostly, such as $\mathrm{SiO}_{2}$ and $\mathrm{RF}$, etc. However, inert materials have low energy and are difficult to meet the requirements for further energy enhancement. Therefore, if the energetic material is used as a skeleton when preparing a nanocomposite energetic material, the energy of the system can be further improved. The researchers successfully prepared 
GAP/HMX [24], NC/HMX [11], and GAP/RDX [25, 26] nanocomposite energetic materials using NC and GAP as gel skeletons.

In this work, $\mathrm{NC}$ and GAP were used as the gel skeleton to obtain an energetic binder with complementary properties by sol-gel method, and then the single-compound explosive ETN was coated in the gel skeleton to form NC/GAP/ETN nanocomposite energetic materials. In the later stage of preparation, the freeze-drying method was adopted. On the premise of maintaining the skeleton structure, the transition from wet gel to aerogel was completed.

\section{$2 \quad$ Experimental}

\subsection{Materials}

Nitrocellulose (NC, 12.6\% N, industrial grade) was purchased from Foshan Junyuan Chemical Co., Ltd (Foshan city, Guangdong province, P.R. China). erythritol-tetranitrate (ETN) was purchased from Gansu Yinguang Chemical Co., Ltd (Baiyin city, Gansu province, P.R. China); Glycidylazide polymer (GAP, $M_{n}=4000$, hydroxyl value of $0.49 \mathrm{mmol} \cdot \mathrm{g}^{-1}$ ) was provided by the $42^{\text {nd }}$ Institute of the Fourth Academy of China Aerospace Science and Technology Corporation. Ethyl acetate (purity of 99.5\%) was purchased from Tianjin Fuyu Fine Chemical Co., Ltd (Tianjin city, P.R. China). Toluene diisocyanate (TDI, purity of 98\%) was purchased from Tianjin Guangfu Chemical Co., Ltd (Tianjin city, P.R. China). Dibutyltin dilaurate (T-12, purity of 95\%) was purchased from Tianjin Baodi Chemical Co., Ltd (Tianjin city, P.R. China). Triethylenediamine (purity of 98\%) was purchased from Sinopharm Group Chemical Reagent Co., Ltd.

\subsection{Fabrication of Nanocomposites}

$\mathrm{NC}$, GAP, and ETN were dissolved completely in $40 \mathrm{~mL}$ of ethyl acetate at ambient temperature in various weight ratios (the ratios of GAP: NC: ETN were 1:1:0.5, 1:1:1, 1:1:1.5). Then, add the measured amount of TDI, the appropriate amount of triethylenediamine solution (0.05 gram of triethylenediamine was dissolved into $1 \sim 2 \mathrm{~mL}$ of ethyl acetate) and T-12 (maintain the $\mathrm{R}$ value $\mathrm{n}(-\mathrm{NCO})$ : $\mathrm{n}(-\mathrm{OH})$ is 0.95 ) into the mixed solution. A wet gel formed after 5 to 10 minutes' standing in thermostatic tank. The wet gel was dried via freeze-drying method (temperature is about $-45^{\circ} \mathrm{C}$, Vacuum degree is $0.01 \mathrm{MPa}$ ) to obtain the NC/GAP/ETN nanocomposite energetic materials. Fig.1 shows the Sketch of fabrication of NC/GAP/ETN nanocomposites.

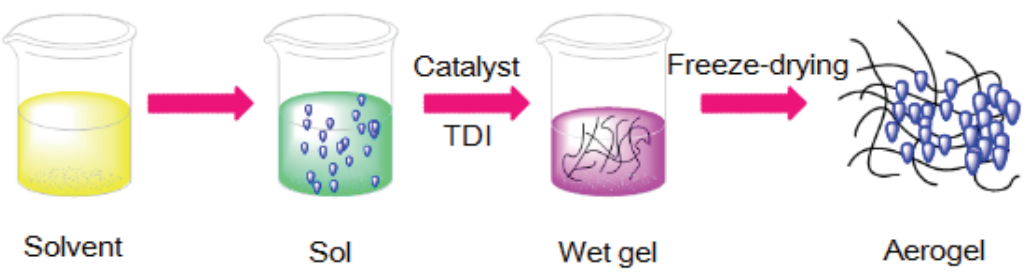

Figure 1. Sketch of fabrication of NC/GAP/ETN nanocomposites.

\subsection{Characterization and Tests}

The morphology was observed with a field-emission scanning electron microscope (SEM, JEOL JSM-7500). The phases of the samples were investigated with an X-ray diffractometer (XRD, Bruker Advance D8) using $\mathrm{Cu} \mathrm{K}$ _a radiation at $40 \mathrm{kV}$ and $30 \mathrm{~mA}$. IR analysis was performed on a Thermo Fischer Scientific Nicolet 6700 infrared spectrometer (potassium bromide tablet). Thermal analysis was performed on a differential scanning calorimeter (DSC, DSC-100) at heating rates of $20^{\circ} \mathrm{C} \cdot \mathrm{min}^{-1}$.

The impact sensitivity of the samples was tested with an HGZ-1 impact instrument. The special height $\left(H_{50}\right)$ represents the height from which a $5 \mathrm{~kg}$ drop-hammer will result in an explosive event in $50 \%$ of the trials. In each determination, 25 drop tests were made in order to calculate the $H_{50}$ and each lot was tested three times to obtain a mean value and a standard deviation. The friction sensitivity of the samples was 
tested with a WM-1 friction instrument, and three test standards were adopted $\left(90 \pm 1^{\circ}, 3.92 \mathrm{MPa}\right)$. In each determination, 50 samples were tested and an explosion probability $(P, \%)$ was obtained. Each lot was tested three times to obtain a mean value and a standard deviation.

\section{$3 \quad$ Results and Discussion}

\subsection{Morphology and Structure}

The morphology and structure of as-prepared samples are probed by SEM, and the images are exhibited in Fig. 2. It is obvious that the microstructure of the composite is a network porous structure, and the ETN particles are dispersed on the gel skeleton. The particles size is about 500nm. Partial particles may have agglomerated, the fractional gel skeletons collapsed and contracted, and the network pores were damaged and could not be fully utilized.
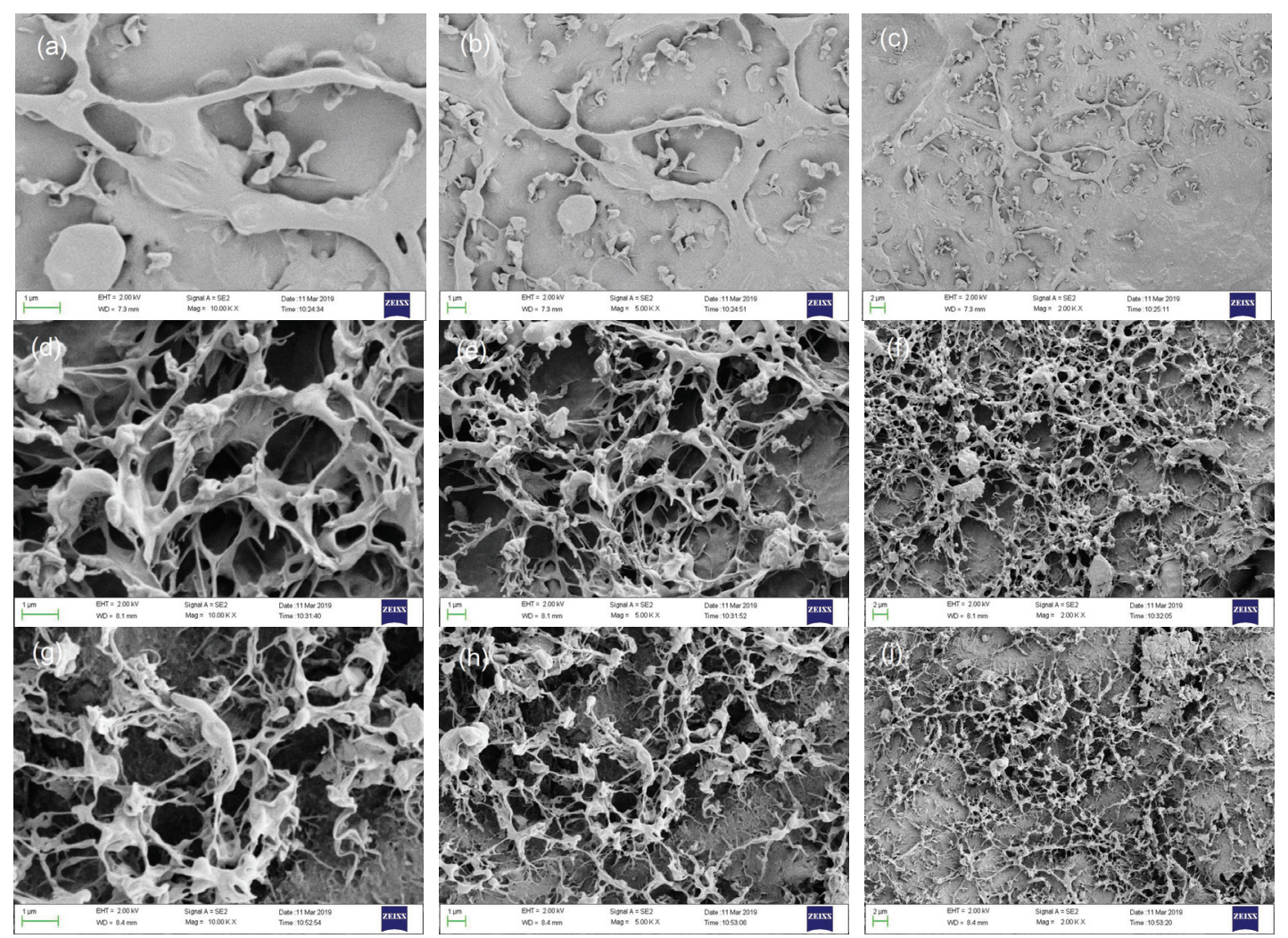

Figure 2. SEM images of nanocomposites: (a, b, c) for $\mathrm{NC}(2 \mathrm{~g}) / \mathrm{GAP}(2 \mathrm{~g}) / \operatorname{ETN}(1 \mathrm{~g})$; (d, e, f) for $\operatorname{NC}(2 \mathrm{~g}) / \mathrm{GAP}(2 \mathrm{~g}) /$ $\operatorname{ETN}(2 \mathrm{~g})$; $(\mathrm{g}, \mathrm{h}, \mathrm{i})$ for $\mathrm{NC}(2 \mathrm{~g}) / \mathrm{GAP}(2 \mathrm{~g}) / \operatorname{ETN}(3 \mathrm{~g})$.

In order to identify whether ETN underwent phase transition during sol-gel process, XRD analysis were performed and the pattern were shown in Fig.3. Fig.3a shows the XRD pattern of raw ETN. It was obvious that raw ETN has numerous sharp crystal diffraction peaks at $12.3^{\circ}, 17.9^{\circ}, 21.7^{\circ}, 24.1^{\circ}, 27.8^{\circ}$ and $33.1^{\circ}$, respectively. The XRD patterns of nanocomposites are shown in Fig.3b. There are no obvious crystal diffraction peaks in the XRD pattern of NC/GAP/ETN when the content of ETN is $1 \mathrm{~g}$. As the ETN content increases, the crystallization peak of ETN becomes more and more obvious, and is the same as the crystallization peak position of the raw ETN. This indicated that the crystal form of ETN has not changed during the gelation process. 

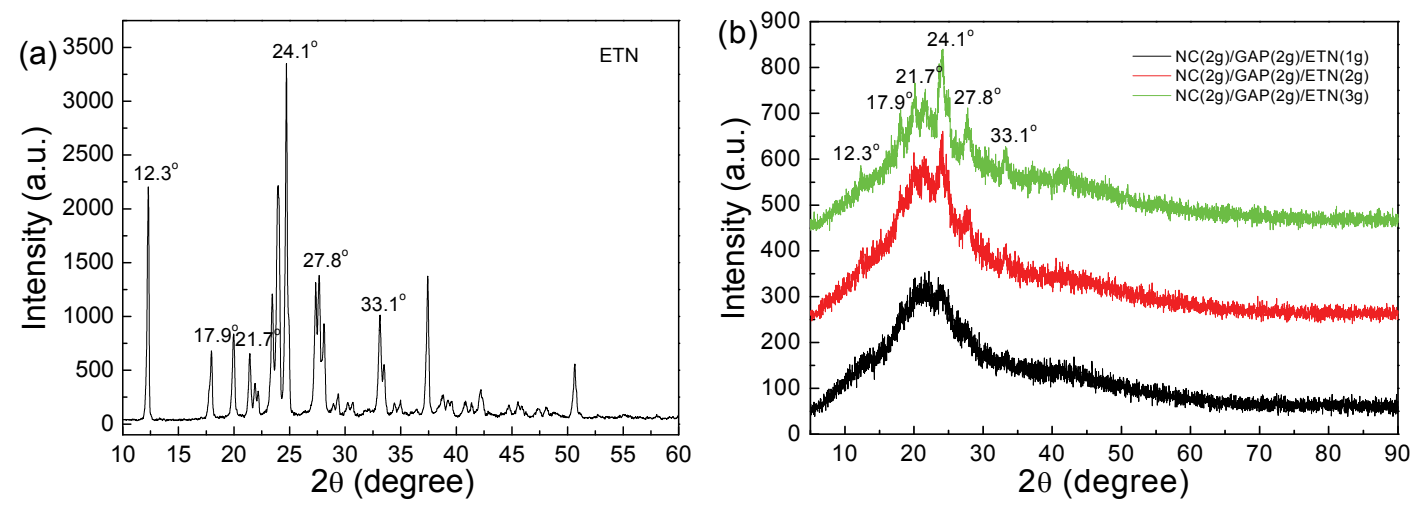

Figure 3. XRD patterns: (a) for raw ETN; (b) for NC/GAP/ETN nanocomposites.

The molecular structure and the functional group of nanocomposites are characterized by IR analyses, and the IR spectra were shown in Fig.4. Specifically, the peak at $3410 \mathrm{~cm}^{-1}$ corresponds to the stretching vibration of $-\mathrm{OH}$, and it illustrates that residual $-\mathrm{OH}$ (in $\mathrm{NC}$ and GAP) were remained in the nanocomposites. The peaks at $1535 \mathrm{~cm}^{-1}$ and $1280 \mathrm{~cm}^{-1}$ ascribed to the shear bending vibration of $-\mathrm{N}-\mathrm{H}$ and the stretching vibration of $\mathrm{C}-\mathrm{N}$ respectively, indicating that the $-\mathrm{OH}$ groups in $\mathrm{NC} / \mathrm{GAP}$ reacted with NCO groups in TDI to form carbamate during the gelation process. The peak located at $2100 \mathrm{~cm}^{-1}$ relates to the stretching vibration of $-\mathrm{N}_{3}$, which is the energetic group in molecules of GAP. The peak at $1670 \mathrm{~cm}^{-1}$ reflects the asymmetrical stretching vibration of $-\mathrm{NO}_{2}$. The peaks located at $2930 \mathrm{~cm}^{-1}$ and $1070 \mathrm{~cm}^{-1}$ are assigned to the asymmetrical stretching vibration of $\mathrm{C}-\mathrm{H}$ bond and the stretching vibration of $-\mathrm{CH}_{2^{-}}$ respectively. The stretching vibration at $1070 \mathrm{~cm}^{-1}$ is $\mathrm{C}-\mathrm{O}$ bond. The peak positions of the three different samples are the same, and the characteristic peaks of ETN are presented in the IR spectra.

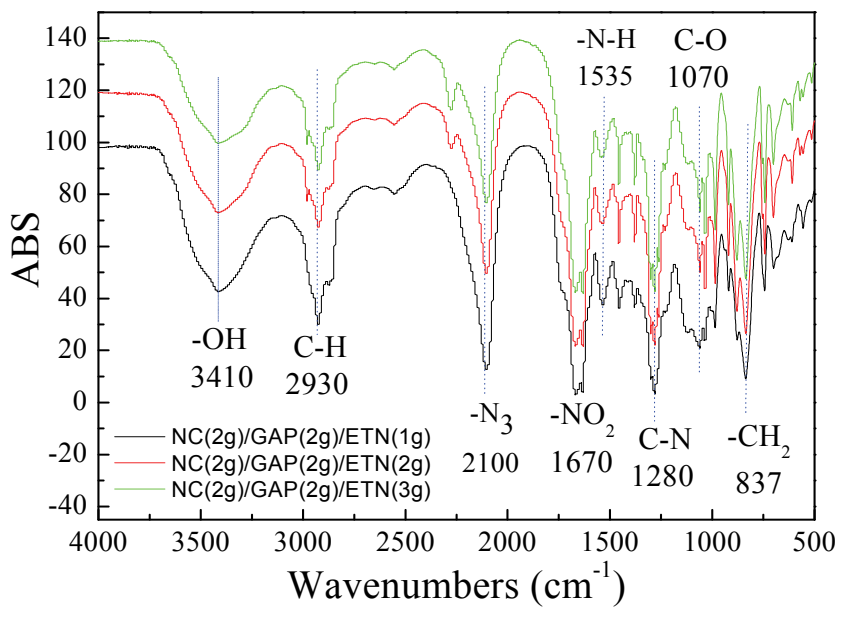

Figure 4. IR spectra of NC/GAP/ETN nanocomposites.

\subsection{Thermal Analysis}

In order to study thermolysis properties of $\mathrm{NC} / \mathrm{GAP} / \mathrm{ETN}$ nanocomposites, thermal analyses are performed and the DSC traces are collected and present in Fig.5. Data of thermal analysis for NC/GAP/ETN nanocomposites are shown in Table 1. It is clear that there is only one exothermic peak in the DSC traces of three different samples. In the $\mathrm{NC} / \mathrm{GAP} / \mathrm{ETN}$ nanocomposites, $\mathrm{NC}$ and GAP are interconnected to form a network structure. Meanwhile, ETN is dispersed on the NC/GAP aerogel skeleton, and the two phases are affected each other by heat. Since the nanometer ETN is enveloped in the $\mathrm{NC} / \mathrm{GAP}$ gel skeleton, the thermal decomposition of $\mathrm{NC}$ and GAP also catalyzes the thermal decomposition of ETN. The thermal decomposition of the two phases has a synergistic effect. We know 
that the peak temperature of ETN thermal decomposition is about $200^{\circ} \mathrm{C}$. The data of thermal analysis shows that the peak temperature of nanocomposites are approximately $62^{\circ} \mathrm{C}, 24^{\circ} \mathrm{C}$ and $41^{\circ} \mathrm{C}$ earlier than raw ETN. Thermal decomposition is closely related to particle size. The initial decomposition temperature of nanometer samples will be advanced. The nitrogen dioxide gas produced by NC decomposition has autocatalytic effect on thermal decomposition. The porous structure of $\mathrm{NC}$ aerogel can adsorb nitrogen dioxide, strengthen autocatalysis and advance the decomposition temperature.
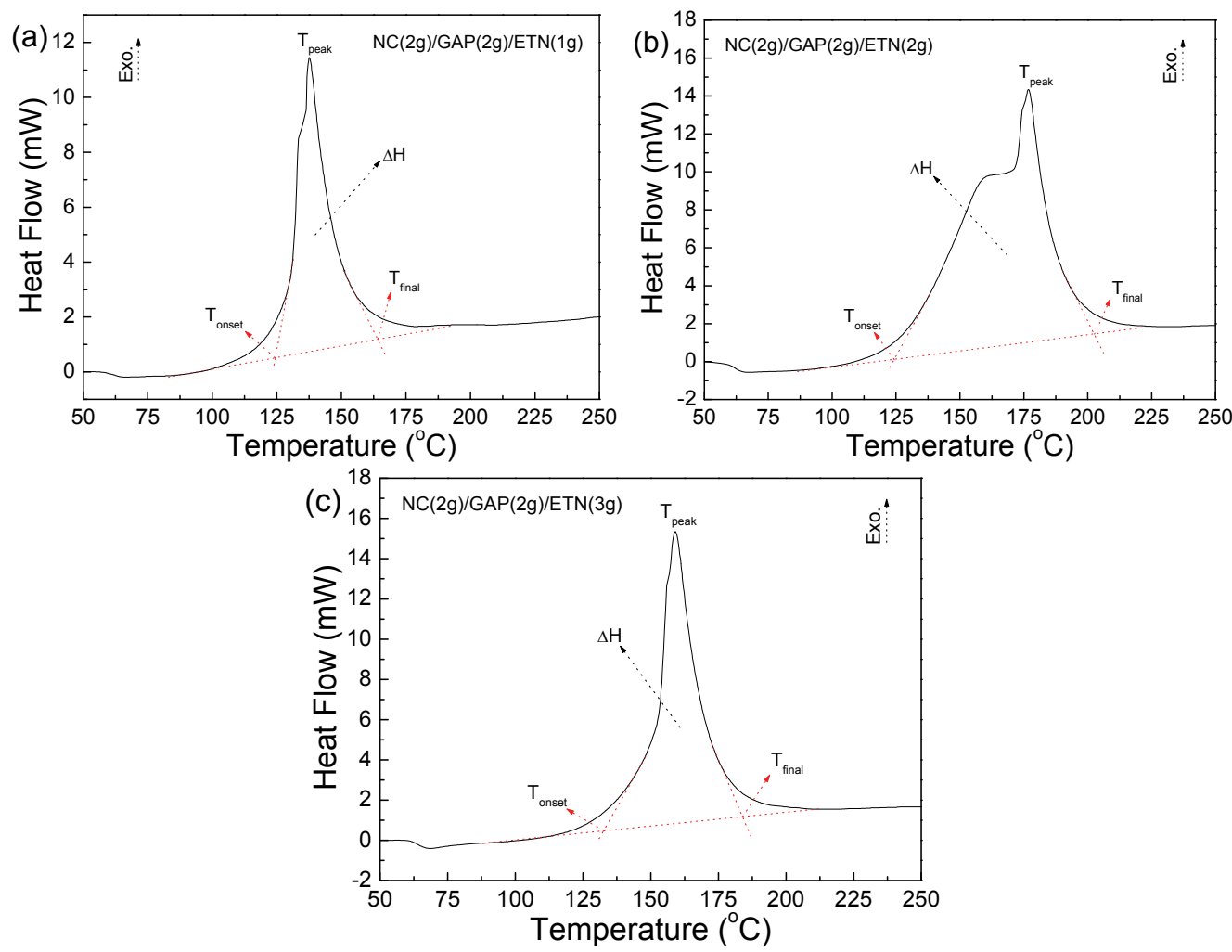

Figure 5. DSC traces of NC/GAP/ETN nanocomposites.

Table 1. Data of thermal analysis for NC/GAP/ETN nanocomposites.

\begin{tabular}{ccccc}
\hline Samples & $T_{\text {onset }}\left({ }^{\circ} \mathrm{C}\right)$ & $T_{\text {peak }}\left({ }^{\circ} \mathrm{C}\right)$ & $T_{\text {final }}\left({ }^{\circ} \mathrm{C}\right)$ & $\Delta H(\mathrm{~J} / \mathrm{g})$ \\
\hline $\mathrm{NC}(2 \mathrm{~g}) / \mathrm{GAP}(2 \mathrm{~g}) / \operatorname{ETN}(1 \mathrm{~g})$ & 124.4 & 137.8 & 164.2 & 226.7 \\
$\mathrm{NC}(2 \mathrm{~g}) / \mathrm{GAP}(2 \mathrm{~g}) / \operatorname{ETN}(2 \mathrm{~g})$ & 124.6 & 176.7 & 202.9 & 354.1 \\
$\mathrm{NC}(2 \mathrm{~g}) / \mathrm{GAP}(2 \mathrm{~g}) / \operatorname{ETN}(3 \mathrm{~g})$ & 132.5 & 159.0 & 184.4 & 322.6 \\
\hline
\end{tabular}

\subsection{Energetic Properties}

\subsubsection{Energy performance}

In order to investigate the energy performance of NC/GAP/ETN nanocomposites, the energy performance such as $I_{s p}, C^{*}, T_{c}, M_{c}$, and $Q_{p}$ were calculated, and the data were shown in Table 2. Fig. 6 shows the energy performances of $\mathrm{NC} / \mathrm{GAP} / \mathrm{ETN}$ nanocomposites as a function of weight percentage of ETN. It is obvious that the $I_{s p}, C^{*}, T_{c}, M_{c}$, and $Q_{p}$ increase with the weight percentage of ETN increasing. This mainly because that the explosive heat $\left(8492 \mathrm{~J} \cdot \mathrm{g}^{-1}\right)$ and oxygen balance $(+5.3 \%)$ of ETN is much higher than $\mathrm{NC}\left(3577 \mathrm{~kJ} \cdot \mathrm{kg}^{-1}\right.$ and $\left.-35 \%\right)$ and GAP $\left(2000 \mathrm{~kJ} \cdot \mathrm{kg}^{-1}\right.$ and $\left.-121.2 \%\right)$. The introduction of energetic materials with negative oxygen balance cannot make the chemical energy of GAP released sufficiently. But the situation will be changed if we add some energetic materials with positive oxygen balance. Fig. 7a illustrates that the combustion of NC (2g) / GAP (2g) / ETN (1g) produces more CO, $\mathrm{H}_{2}$ 
and less $\mathrm{CH}_{4}$ and $\mathrm{C}$, which confirms that it is a negative oxygen balance formula and is beneficial to the increase of energy conversion efficiency of propellants. Fig. $7 \mathrm{~b}$ shows that the content of $\mathrm{CO}_{2}$ in the combustion products increases compared with NC (2g) / GAP (2g) / ETN (1g), the content of $\mathrm{CH}_{4}$ and $\mathrm{H}_{2}$ decreases, and $\mathrm{C}$ disappear. The result manifest that the oxygen balance of the system has increased but is still negative. The content of $\mathrm{CO}_{2}$ and $\mathrm{H}_{2} \mathrm{O}$ in Fig. 7c is higher in comparison with $\mathrm{NC}(2 \mathrm{~g}) / \mathrm{GAP}(2 \mathrm{~g}) /$ ETN $(1 \mathrm{~g})$ and NC $(2 \mathrm{~g}) / \mathrm{GAP}(2 \mathrm{~g}) / \mathrm{ETN}(2 \mathrm{~g})$, indicating that the oxygen balance is the highest when the content of ETN is $3 \mathrm{~g}$. But the system still contains $\mathrm{H}_{2}$ and $\mathrm{CO}$, so its oxygen balance is still negative. It is obvious that the nanocomposite containing $1 \mathrm{~g}$ ETN generates a large amount of toxic gas and solid carbon when it reacts, which is not conducive to the actual use of explosives. Compared with NC (2g) / GAP (2g) / ETN (1g), the content of $\mathrm{CH}_{4}$ decrease and the $\mathrm{C}$ disappeared in the combustion products of sample with $2 \mathrm{~g}$ ETN, indicating that the combustion rate was improved. Meanwhile, the explosion heat of the sample is also significantly improved. For $\mathrm{NC}(2 \mathrm{~g}) / \mathrm{GAP}(2 \mathrm{~g}) / \mathrm{ETN}(3 \mathrm{~g})$, the content of $\mathrm{CO}$ and $\mathrm{H}_{2}$ is reduced, while the content of $\mathrm{CO}_{2}$ and $\mathrm{H}_{2} \mathrm{O}$ increasing, and the $\mathrm{CH}_{4}$ disappeared. Hence, the burning rate the sample with $3 \mathrm{~g}$ ETN is better than the first two samples. At the same time, the explosion heat is higher than the previous two samples obviously. In brief, the increase of ETN content is beneficial to improve the energy performance of nanocomposite energetic materials.

Table 2. Energy performance of NC/GAP/ETN nanocomposites.

\begin{tabular}{cccccc}
\hline Samples & $I_{s p}\left(\mathrm{~N} \cdot \mathrm{s} \cdot \mathrm{kg}^{-1}\right)$ & $C^{*}\left(\mathrm{~m} \cdot \mathrm{s}^{-1}\right)$ & $T_{c}(\mathrm{~K})$ & $M_{c}\left(\mathrm{~g} \cdot \mathrm{mol}^{-1}\right)$ & $Q_{p}\left(\mathrm{~kJ} \cdot \mathrm{kg}^{-1}\right)$ \\
\hline $\mathrm{NC}(2 \mathrm{~g}) / \mathrm{GAP}(2 \mathrm{~g}) / \operatorname{ETN}(1 \mathrm{~g})$ & 2092.3 & 1336.3 & 1839 & 20.296 & 2816.5 \\
$\mathrm{NC}(2 \mathrm{~g}) / \mathrm{GAP}(2 \mathrm{~g}) / \mathrm{ETN}(2 \mathrm{~g})$ & 2215.8 & 1409.6 & 2268 & 21.818 & 3595.8 \\
$\mathrm{NC}(2 \mathrm{~g}) / \mathrm{GAP}(2 \mathrm{~g}) / \mathrm{ETN}(3 \mathrm{~g})$ & 2299.1 & 1484.9 & 2516 & 22.412 & 4035.2 \\
\hline
\end{tabular}

$I_{s p}$ is Standard specific impulse; $C^{*}$ is Characteristic speed; $T_{c}$ is Combustion chamber temperature; $M_{c}$ is Average molecular weight of combustion products; $Q_{p}$ is Explosion heat. All the parameters were calculated by means of software ProPep 3.0 at condition of $P_{c} / P_{e}=70 / 1\left(P_{e}=0.1 \mathrm{MPa}\right)$ and $T_{0}=298 \mathrm{~K}$.
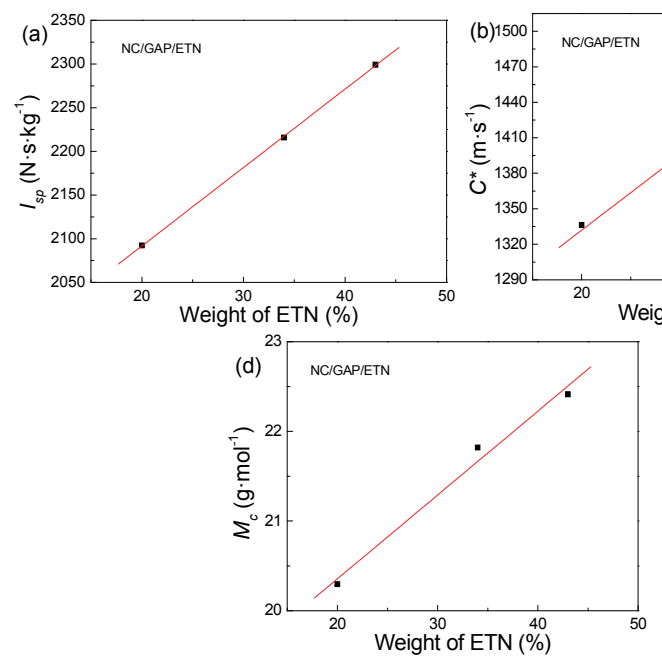
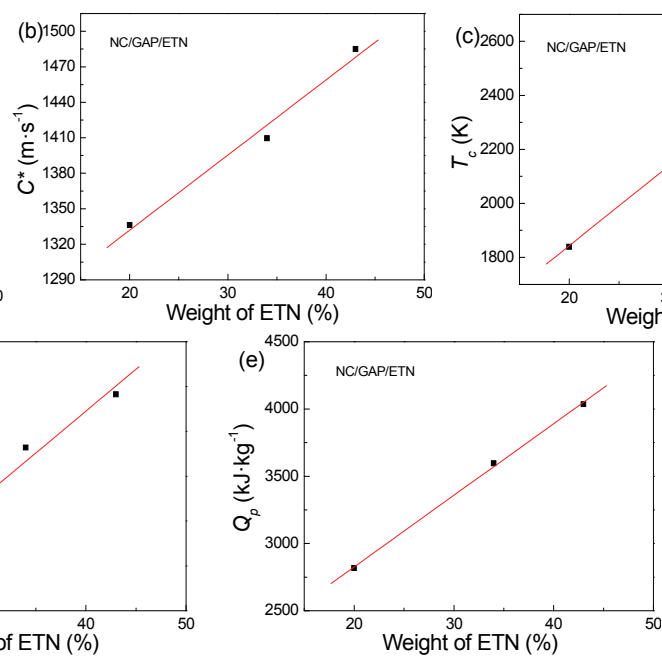

Figure 6. Energy performances of NC/GAP/ETN nanocomposites as a function of weight percentage of ETN. 

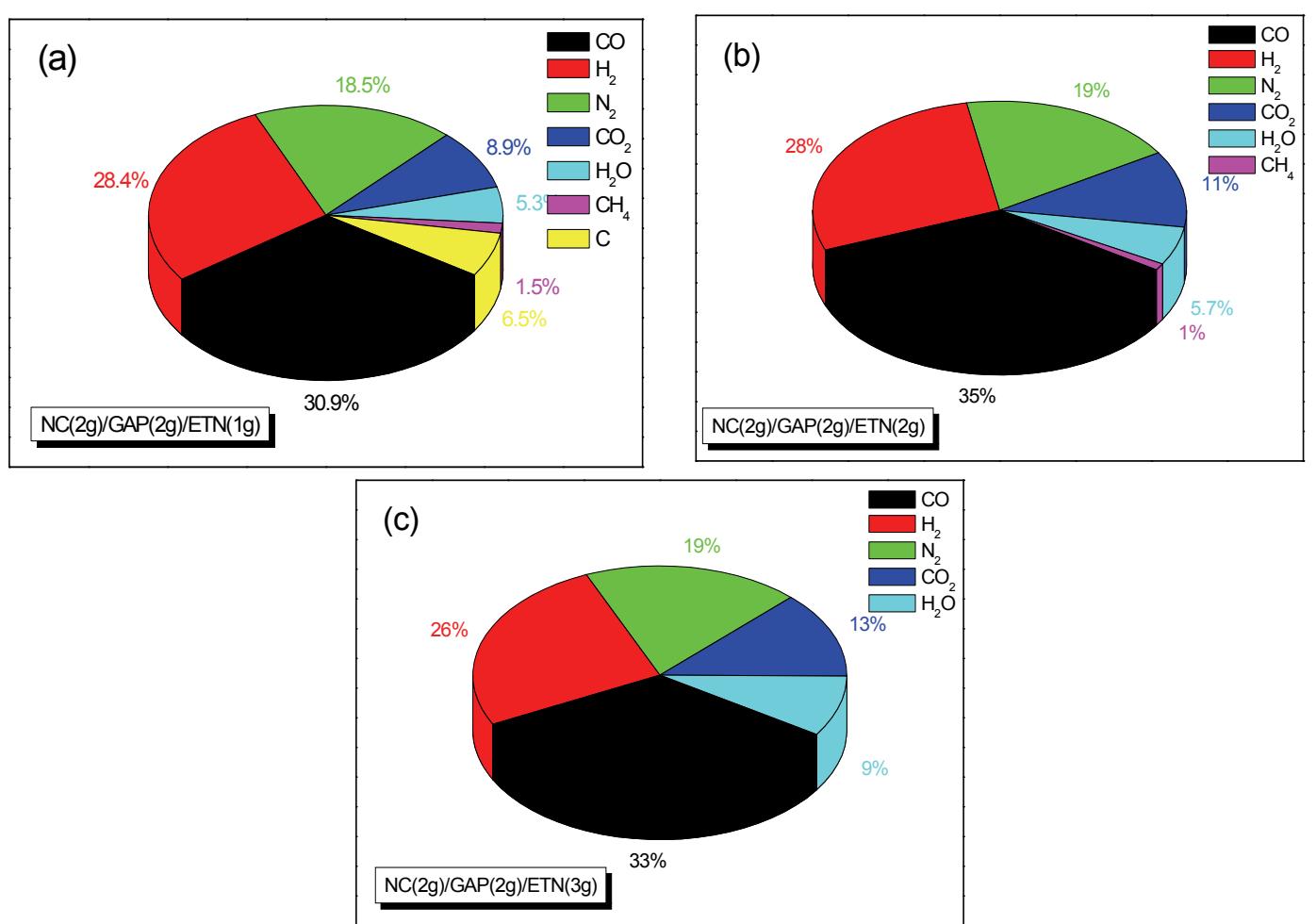

Figure 7. Combustion products and their molar ratios for nanocomposites. The results in Fig.7 were calculated by means of software ProPep 3.0 at condition of $P_{c} / P_{e}=70 / 1\left(P_{e}=0.1 \mathrm{MPa}\right)$ and $T_{0}=298 \mathrm{~K}$.

\subsubsection{Mechanical sensitivities}
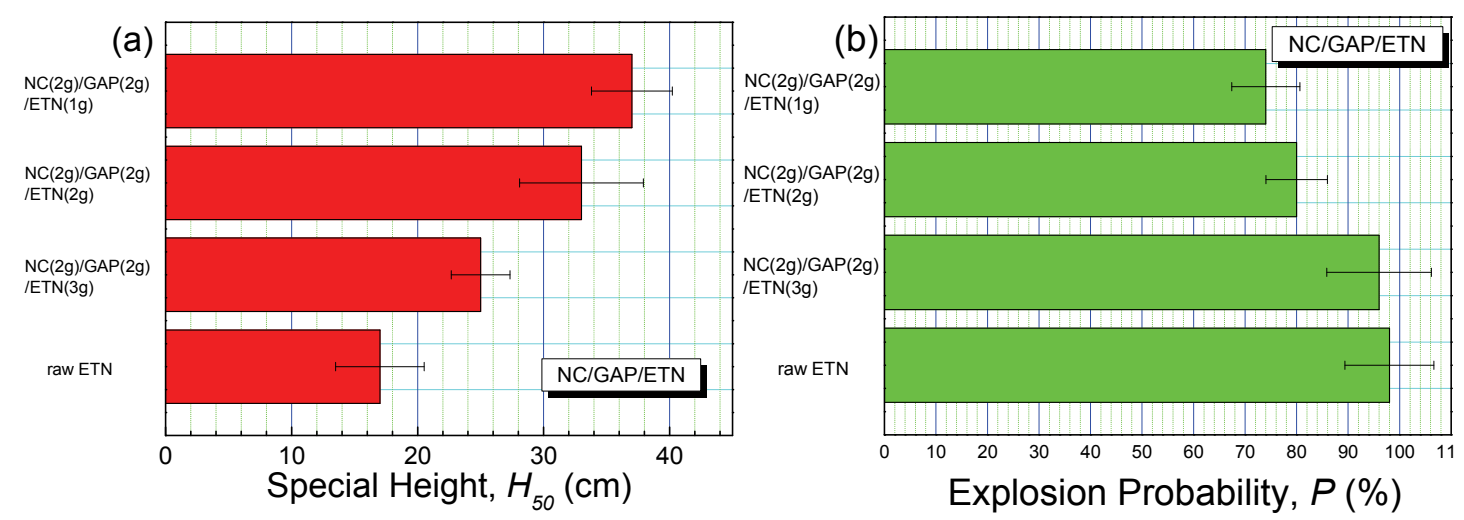

Figure 8. Mechanical sensitivities of samples: (a) impact sensitivity; (b) friction sensitivity.

The mechanical sensitivities of nanocomposites were tested, and the special height $\left(H_{50}\right)$ and the explosion probability $(P)$ of NC/GAP/ETN were showed in Fig. 8. Higher $H_{50}$ value means lower impact sensitivity and higher $P$ value means higher friction sensitivity. The $H_{50}$ of three kinds of composite materials with different formulas are all higher than raw ETN, illustrating that the formation of the gel skeleton effectively improves the special height of the energetic material and reduces its impact sensitivity. It mainly because ETN particles was dispersed in the insensitive NC/GAP gel skeleton and the particle size were controlled at nanometer level, which dissipated the impact strength. The higher the content of ETN, the higher the percentage of explosion. The explosive probability of three formulas are all lower than raw ETN, so the friction sensitivity reduced than raw ETN. It is clear that the impact sensitivity and friction sensitivity becomes higher with the content of ETN increasing. This probably because that the gel 
skeleton cannot completely encapsulate the ETN as the content of ETN increases, and part of the ETN precipitates from the gel skeleton. In brief, the $\mathrm{NC} / \mathrm{GAP} / \mathrm{ETN}$ nanocomposite materials are propellant additive that is more insensitive than raw ETN.

\section{Conclusions}

In a word, $\mathrm{NC}$ and GAP form a gel skeleton with complementary properties, ETN is dispersed on the gel skeleton, and the two phases are affected by heat. Since nano-ETN is entrapped in the gel skeleton of NC and GAP, the thermal decomposition of NC and GAP also catalyzes the thermal decomposition of ETN. The thermal decomposition of the two phase has synergistic effect. Thermal decomposition is closely related to particle size. The initial decomposition temperature of the sample is advanced. The nitrogen dioxide gas generated by the $\mathrm{NC}$ decomposition has an autocatalytic effect on thermal decomposition, and the porous structure of the $\mathrm{NC}$ aerogel can adsorb nitrogen dioxide, enhance the autocatalysis, and advance the decomposition temperature. The explosive heat $\left(8492 \mathrm{~J} \cdot \mathrm{g}^{-1}\right)$ and oxygen balance $(+5.3 \%)$ of ETN is much higher than NC $\left(3577 \mathrm{~kJ} \cdot \mathrm{kg}^{-1}\right.$ and $\left.-35 \%\right)$ and GAP $\left(2000 \mathrm{~kJ} \cdot \mathrm{kg}^{-1}\right.$ and $\left.-121.2 \%\right)$, so the energy performance will be higher with the content of ETN increasing. The NC/GAP gel skeleton acts as a protective and buffering agent for ETN particles during external impact or frictional stimulation, so the nanocomposites are safety than raw ETN. Therefore, the nanocomposite energetic materials are high energy and insensitive composite propellants additives.

Acknowledgement. This research was supported by the Weapon Equipment Pre-Research Fund of China (Grant No. 6140656020201).

\section{References}

1. S. J. Lin, C. Y. Wen and P. M. Wang, "High-level production of erythritol by mutants of osmophilic Moniliella sp," Process Biochemistry, vol. 45, no. 6, pp. 973-979, 2010.

2. J. C. Oxley, J. L. Smith and A. C. Brown, "Eutectics of Erythritol Tetranitrate," The Journal of Physical Chemistry C, vol. 121, no. 30, pp. 16137-16144, 2017.

3. V. W. Manner, D. N. Preston and B. C. Tappan, "Explosive Performance Properties of Erythritol Tetranitrate (ETN)," Propellants Explosives Pyrotechnics, vol. 40, no. 4, pp. 460-462, 2015.

4. V. W. Manner, B. C. Tappan and B. L. Scott, "Crystal Structure, Packing Analysis, and Structural-Sensitivity Correlations of Erythritol Tetranitrate," Crystal Growth $\&$ Design, vol. 14, no. 11, pp. 6154-6160, 2014.

5. J. C. Oxley, D. Furman and A. C. Brown, "Thermal Decomposition of Erythritol Tetranitrate: A Joint Experimental and Computational Study," The Journal of Physical Chemistry C, vol. 121, no. 30, pp. 16145-16157, 2017.

6. R. Matyáš, A. Lyčka and R. Jirásko, "Analytical Characterization of Erythritol Tetranitrate, an Improvised Explosive," Journal of Forensic Sciences, vol. 61, no. 3, pp. 759-764, 2016.

7. J. B. Oleske, B. T. Smith and J. Barber, "Identifying Raman and Infrared Vibrational Motions of Erythritol Tetranitrate," Applied Spectroscopy, vol. 69, no.12, pp.1397-1402, 2015.

8. Y. A. Gruzdkov and Y. M. Gupta, "Vibrational Properties and Structure of Pentaerythritol Tetranitrate," The Journal of Physical Chemistry A, vol. 105, no. 25, pp. 6197-6202, 2001.

9. I. A. Fedorov, T. P. Fedorova and Y. N. Zhuravlev, "Hydrostatic Pressure Effects on Structural and Electronic Properties of ETN and PETN from First Principles Calculations," The Journal of Physical Chemistry A, vol. 120, no. 20, pp. 3710-3717, 2016.

10. L. L. Hench and J. K. West, "The sol-gel process," Chemical Reviews, vol. 90, no. 1, pp. 33-72, 1990.

11. Y. Wang, X. L. Song and D. Song, "Synthesis, thermolysis, and sensitivities of HMX/NC energetic nanocomposites," Journal of Hazardous Materials, vol. 312, pp. 73-83, 2016.

12. J. Zhang, G. C. Yang and F. D. Nie, "Preparation of RDX/RF Nanocomposite Energetic Particles by Emulsion-sol-gel Technique," Chinese Journal of Energetic Materials, vol. 18, no. 6, pp. 643-647, 2010.

13. X. L. Song, Y. Wang and S. S. Zhao, "Characterization and Thermal Decomposition of Nanometer 2,2' , 4,4' , 6,6' -Hexanitro-Stilbene and 1,3,5-Triamino-2,4,6-Trinitrobenzene Fabricated by a Mechanical Milling Method," Journal of Energetic Materials, vol. 36, no. 2, pp. 179-190, 2018.

14. B. J. Ye, C. W. An and Y. R. Zhang, "One-Step Ball Milling Preparation of Nanoscale CL-20/Graphene Oxide for 
Significantly Reduced Particle Size and Sensitivity," Nanoscale Research Letters, vol. 13, no. 1, pp. 42, 2018.

15. J. Liu, W. Jiang and J. B. Zeng, "Effect of Drying on Particle Size and Sensitivities of Nano hexahydro-1,3,5-trinitro-1,3,5-triazine," Defence Technology, vol. 10, no. 1, pp. 9-16, 2014.

16. X. L. Song, Y. Wang and C. W. An, "Thermochemical properties of nanometer CL-20 and PETN fabricated using a mechanical milling method," AIP Advances, vol. 8, no. 6, pp. 065009, 2018.

17. J. K. S. Wong, R. Sandri and J. A. Newman, "A New Experimental Method for the Investigation of Fuel Spray Evaporation," AIAA Journal, vol. 12, no. 3, pp. 269-274, 1972.

18. F. Mohandes and M. Salavatiniasari, "Freeze-drying synthesis, characterization and in vitro bioactivity of chitosan/graphene oxide/hydroxyapatite nanocomposite," RSC Advances, vol. 38, no. 49, pp. 4501-4509, 2014.

19. H. Gao, Q. H. Wang and X. Ke, "Preparation and characterization of an ultrafine HMX/NQ co-crystal by vacuum freeze drying method," RSC Advances, vol. 7, no. 73, pp. 46229-46235, 2017.

20. H. Gao, P. Du and X. Ke, "A Novel Method to Prepare Nano-sized CL-20/NQ Co-crystal: Vacuum Freeze Drying," Propellants Explosives Pyrotechnics. Vol. 42, no. 8, 2017.

21. G. C. Yang, F. D. Nie and H. Hui, "Preparation and Characterization of Nano-TATB Explosive," Propellants Explosives Pyrotechnics, vol. 31, no. 5, pp. 390-394, 2010.

22. J. Rajan, P. S. Archana, A. L. Viet, "Functional Films of Polymer-Nanocomposites by Electrospinning for Advanced Electronics, Clean Energy Conversion, and Storage," Advanced Materials Research, vol. 545, pp. 21-26, 2012.

23. J. Yao, J. Liu and Y. X. Wang, "Electrostaticspray preparation and properties of RDX/DOS composites," Defence Technology, vol. 13, no. 4, pp. 268, 2017.

24. T. Chen, W. Jiang and P. Du, "Facile preparation of 1,3,5,7-tetranitro-1,3,5,7-tetrazocane/ glycidylazide polymer energetic nanocomposites with enhanced thermolysis activity and low impact sensitivity," RSC Advances, vol. 7, no. 10, pp. 5957-5965, 2017.

25. M. M. Li, F. S. Li and R. Q. Shen, "Molecular dynamics study of the structures and properties of RDX/GAP propellant," Journal of Hazardous Materials, vol. 186, no. 2-3, pp. 2031-2036, 2011.

26. G. P. Li, M. H. Liu, R. Zhang, "Synthesis and properties of RDX/GAP nano-composite energetic materials," Colloid \& Polymer Science, vol. 293, no. 8, pp. 2269-2279, 2015. 